\title{
LncRNA-AK149641 associated with airway inflammation in an OVA-induced asthma mouse model
}

\author{
Jie Zhang ${ }^{1,2} \cdot$ Yao Zhou ${ }^{1} \cdot$ Haiyan Gu ${ }^{1} \cdot$ Jiamin Zhang ${ }^{1} \cdot$ Heng Tang ${ }^{1} \cdot$ Qiangquan Rong ${ }^{3} \cdot$ Lina Gu $^{4} \cdot$ Jing Pan $^{1,2}$. \\ Deyu Zhao ${ }^{1} \cdot$ Feng Liu ${ }^{1}$
}

Received: 9 April 2020 / Accepted: 3 July 2020 / Published online: 14 September 2020

(C) The Author(s) 2020

\begin{abstract}
Asthma is defined as a heterogeneous disease, usually characterized by chronic airway inflammation. Long noncoding RNAs (lncRNAs) play important roles in various biological processes. To know more about the relationships between lncRNAs and asthma, gene microarray analysis was performed to screen differentially expressed lncRNAs between the lung tissue of ovalbumin (OVA) mice and control mice. Further studies showed that downregulating differentially expressed lncRNA-AK149641 by adeno-associated virus 6 (AAV6) in OVA mice inhibited airway inflammation, with improved airway compliance and resistance, diminished infiltration of inflammatory cells, as well as less secretions of mucus, tumor necrosis factor alpha (TNF- $\alpha)$ and interleukin-6 (IL-6). Moreover, the activity of nuclear factor-kappa B (NF-KB) in the lung tissue was reduced after downregulating lncRNA-AK149641. In conclusion, we proposed that downregulation of IncRNA-AK149641 attenuated the airway inflammatory response in an OVA-induced asthma mouse model, probably in association with modulation of the NF-KB signaling pathway.
\end{abstract}

Keywords lncRNA-AK149641 · OVA-induced asthma mouse model $\cdot$ TNF- $\alpha \cdot$ IL-6 and NF-kB signaling pathway

\section{Introduction}

Bronchial asthma are a heterogeneous group of respiratory diseases, which is common among children and whose incidence is increasing in developed nations (Wilson et al. 2006). It is characterized by airway inflammation and airway hyperresponsiveness (AHR) with symptoms including recurrent wheeze, cough, and shortness of breath, together with variable expiratory airflow limitation (Kim et al. 2010). It has been widely accepted that inflammatory cells, such as

Jie Zhang and Yao Zhou contributed equally to this work.

Deyu Zhao

zhaodeyu98@126.com

Feng Liu

axsliu@163.com

1 Department of Respiratory Medicine, Children's Hospital of Nanjing Medical University, Nanjing 210008, Jiangsu, China

2 Department of Emergency Medicine, Children's Hospital of Nanjing Medical University, Nanjing 210008, Jiangsu, China

3 Department of Pediatrics, Gaochun People's Hospital, Nanjing 211300, Jiangsu, China

4 Wuxi Children's Hospital, Wuxi 214000, Jiangsu, China eosinophils and mast cells (Doherty and Croft 2011; Galli et al. 2011; Kim et al. 2010), as well as various cytokines, including TNF- $\alpha$ and IL-6, take part in the airway inflammatory response of asthma (Doganci et al. 2005; Rameshwar et al. 2014; Rincon and Irvin 2012).

LncRNAs are RNAs with more than 200 nucleotides without a protein-coding capability (Yang et al. 2014). Due to a lack of reading frames, lncRNAs were initially considered non-functional. However, accumulating evidence has suggested that they participate in a variety of biological and pathological processes, such as cancer (Zhou et al. 2015c), selfrenewal of embryonic stem cells (Tu et al. 2018), metabolism (Yin et al. 2015), and immune responses (Houtman et al. 2018). Moreover, an increasing number of studies have reported that lncRNAs take part in asthmatic airway inflammation. For example, the IncRNA BCYRN1 promotes the proliferation and migration of asthmatic rat airway smooth muscle cells (ASMCs) by upregulating the expression of transient receptor potential (TRPC1) (Zhang et al. 2016).

TNF- $\alpha$ and IL-6, highly expressed in the asthmatic subjects (Doganci et al. 2005; Russo and Polosa 2005), are important pro-inflammatory cytokines in regulating asthma pathophysiology. Studies show that single nucleotide polymorphisms (SNPs) of them may be risk factors for asthma susceptibility 
(Chiang et al. 2013; Daneshmandi et al. 2011; Li et al. 2006). IL-6, an inhibitor of T helper 1 (Th1) differentiation, is a significant modulator of effector CD4+ T cell differentiation and IL-4 production during the process of Th2 differentiation. The ability of regulating Th1 and Th2 differentiation makes IL-6 become a crucial factor in the onset of asthma (Dienz and Rincon 2009; Lee et al. 2017; Neveu et al. 2010).

In our previous unpublished study, we screened differentially expressed lncRNAs in LPS-stimulated P815 mast cells and control P815 mast cells. Subsequent study in vitro indicated that after downregulating the differentially expressed lncRNA-AK149641 in P815 mast cells, the concentrations of TNF- $\alpha$ and IL- 6 were significantly reduced in supernatants, suggesting roles of lncRNA-AK149641 in inflammatory response. In this study, microarray analysis also showed that lncRNA-AK149641 expression was twofold higher in OVA mice compared to control mice.

Based on the previous study, in order to further investigate the function and possible mechanism of IncRNA-AK149641 in mediating the airway inflammatory response in vivo, an OVA-induced asthma mouse model was established and studied.

\section{Materials and methods}

\section{Mice}

Specific pathogen-free (SPF) female BALB/c mice, 6-8week-old, were purchased from the animal core facility of Nanjing Medical University (Nanjing, China), and housed in pathogen-free conditions. All mice were fed with OVA-free food and water for approximately one week before the experiments were started. The study reported here complies with ethical requirements and is permitted by the Animal Ethical and Welfare Committee (AEWC) of Nanjing Medical University (Approval No. IACUC-1703005).

\section{Establishment of OVA-induced asthma mouse model}

Mice were sensitized and challenged as described previously (Li et al. 2015; Suh et al. 2016) with slight modification. That is, BALB/c mice were sensitized at day 0 and day 14 by intraperitoneal (i.p.) injections of the model allergen OVA (V grade) (Sigma-Aldrich, St. Louis, MO, USA) $(20 \mu \mathrm{g}$ OVA, $2 \mathrm{mg} \mathrm{Al}(\mathrm{OH})_{3}$ plus phosphate buffered solution (PBS) with a total volume of $0.2 \mathrm{ml}$ ). By using an ultrasonic nebulizer (PARI GmbH, Starnberg, Germany), mice were challenged for 20-25 min via the airway by an aerosol consisting of $1 \%$ OVA on four successive days (day 27 to day 30). Non-OVA mice received the same schedule for sensitization and challenge with PBS instead of OVA.

\section{LncRNA microarray assay}

Triplicate RNA samples extracted from OVA mice and normal mice were used for IncRNA microarray assays. It was performed by Kangchen Bio-tech Co., Ltd. (Shanghai, China). The thresholds set to identify upregulated or downregulated genes were fold changes of $\geq 2.0$ or $\leq 0.5$, respectively.

\section{AAV6}

Recombinant AAV6, with strong affinity for lung tissue and expressed permanently, acted as a vector. It was constructed and packaged by Hanbio Biotechnology Co., Ltd. (Shanghai, China), with a titer over $1 \times 10^{12} \mathrm{vg} / \mathrm{ml}$, containing green fluorescent protein (GFP) expression sequence label and sequence of interest. The interest sequence referred to invalid sequence (shRNA-NC) or interference sequence of lncRNAAK149641 (shRNA-AK149641). ShRNA-AK149641 was used to downregulate the expression of lncRNA-AK149641, while shRNA-NC, without biological significance, was used as control. The sequences of shRNA-NC and shRNAAK149641 are summarized in Table 1.

\section{Infection of AAV6}

Two days before the first sensitization (day -2 ), mice were infected with AAV6 to express the interest sequences. After the mice were fully anesthetized ( $4 \%$ chloral hydrate, $0.1 \mathrm{mg} /$ $10 \mathrm{~g}$ ) by i.p. injections, with the help of endotracheal intubation, $50 \mu 1$ liquid containing AAV6 was infused to the lung.

\section{Groups}

Mice were randomly divided into four groups for different interferences: (1) the control mice (NC): infected by AAV6 containing the sequence of shRNA-NC (AAV6-shRNA-NC),

Table 1 The sequences of shRNA-NC and shRNA-AK149641

\begin{tabular}{ll}
\hline Sequence \\
\hline shRNA-NC & Top strand: gatccGTTCTCCGAACGTGTCACGT \\
& AATTCAAGAGATTACGTGACACGT \\
TCGGAGAATTTTTc & Bottom strand: aattcAAAAAATTCTCCGA \\
ACGTGTCACGTAATCTCTTGAATT & ACGTGACACGTTCGGAGAACg \\
shRNA-AK149641 & Top strand: GatccGGTTTGACAGTAGC \\
& TAGTTTCAAGAGAAACTAGCTAC \\
& TGTCAAACCTTTTTTC \\
Bottom strand: aattgAAAAAAGGTTGAC \\
AGTAGCTAGTTTCTCTTGAAAACT \\
AGCTACTGTCAAACCg
\end{tabular}


sensitized and challenged by PBS; (2) the mice with lncRNAAK149641 downregulated (shRNA-AK149641): infected by AAV6 containing the interference sequence of shRNAAK149641 (AAV6-shRNA-AK149641), sensitized and challenged by PBS; (3) the OVA mice (OVA): infected by AAV6shRNA-NC, sensitized and challenged by OVA; (4) the OVA mice with IncRNA-AK149641 downregulated (OVA+ shRNA-AK149641): infected by AAV6-shRNAAK149641, sensitized and challenged by OVA. Mice were sacrificed $24 \mathrm{~h}$ after the last challenge.

\section{Total RNA extraction and qRT-PCR analysis}

Total RNA was extracted from the lung and other organs by using TRIzol reagent (Invitrogen, Carlsbad, CA, USA), according to the manufacturer's instructions. One thousand nanograms of total RNA was reverse transcribed in a final volume of $20 \mu \mathrm{l}$ using a RevertAid First Strand cDNA Synthesis Kit (Thermo Fisher Scientific, Waltham, MA, USA). Quantitative real-time polymerase chain reaction (qRT-PCR) was performed using the FastStart Universal SYBR Green Master (Roche, Switzerland) on an ABI 7500 system (Applied Biosystems, Carlsbad, CA, USA) according to the manufacturer's instructions. The expression level of IncRNA-AK149641 was normalized to that of GAPDH and calculated using the $2^{-\Delta \Delta C T}$ method. The sequences of the primers used for IncRNA amplification are summarized in Table 2.

\section{Measurement of AHR to methacholine}

Mice were anesthetized with $1.0 \%$ pentobarbital sodium by i.p. injection $24 \mathrm{~h}$ after the last challenge, and then AHR was measured by the AniRes2005 Lung Function System (Bestlab, Beijing, China), according to the manufacturer's instructions and previous study (Li et al. 2013). Airway responsiveness was examined by airway compliance (Cydn) and expiratory airway resistance $\left(\mathrm{R}_{\mathrm{e}}\right)$.

\section{Collection and analysis of bronchoalveolar lavage fluid (BALF)}

Airway inflammation was assessed $24 \mathrm{~h}$ after the last challenge. BALF was collected by delivering $0.8 \mathrm{ml}$ cold PBS

Table 2 The sequences of the primers used for lncRNA amplification

Sequence

AK149641

Forward:5'-GATGCTCTGGAACTGGAGGT-3'

Reverse: 5'-GCGATGTCTCTGCTGGAAG-3'

GAPDH

Reverse: 5'-TGGTCCAGGGTTTCTTACTCC-3'

through endotracheal intubation and gently aspirating the fluid. The lavage was repeated three times. The recovery rate was about $80 \%$.

\section{Histopathological analysis}

The lung tissues were obtained to evaluate pathological changes in the lung parenchyma. Samples were fixed in $4 \%$ neutral buffered formalin, processed, paraffin embedded, and sectioned at $4-\mu \mathrm{m}$ thickness. Three different staining methods, that is, hematoxylin and eosin (H\&E) staining, periodic acid-schiff (PAS) staining, and immunohistochemical staining of TNF- $\alpha$ and IL- 6 were used for light microscopic evaluation, as described in previous studies (Ford et al. 2001; Myou et al. 2003). All sample slides for comparison were assessed under the same magnification.

\section{Western blot analysis}

Total protein was separated and transferred onto nitrocellulose membranes (Millipore, MA, USA). Membranes were blocked with $5.0 \%$ non-fat milk for two hours at room temperature and incubated overnight at $4^{\circ} \mathrm{Cwith}$ specific antibodies. After washing with TBST, membranes were incubated with a horseradish peroxidase-conjugated anti-rabbit antibody at room temperature for two hours. Signals were detected on a gel imaging system using an ECL western blotting substrate (Thermo Fisher Scientific, Waltham, MA, USA).

\section{Statistical analysis}

Statistical analysis was performed by using SPSS 20.0 software (SPSS Inc., Chicago, IL, USA). Comparisons of groups were made using Student's $t$ test and multiple comparisons were made using one-way analysis of variance (ANOVA). A difference was considered statistically significant if the $P$ value was $<0.05$.

\section{Results}

\section{Differentially expressed IncRNAs between the lung tissue of OVA mice and normal control mice}

To identify lncRNAs that may be involved in the inflammatory response of asthma, triplicate RNA samples extracted from the lung tissue of OVA mice and control mice were used for IncRNA microarray assays. The heat map of significantly differentially expressed lncRNAs was presented in Fig. 1A. Differentially expressed IncRNAs were classified into five categories: intergenic, exon sense-overlapping, intronic antisense, natural antisense, and bidirectional lncRNAs. Bioinformatics analysis such as gene 
a

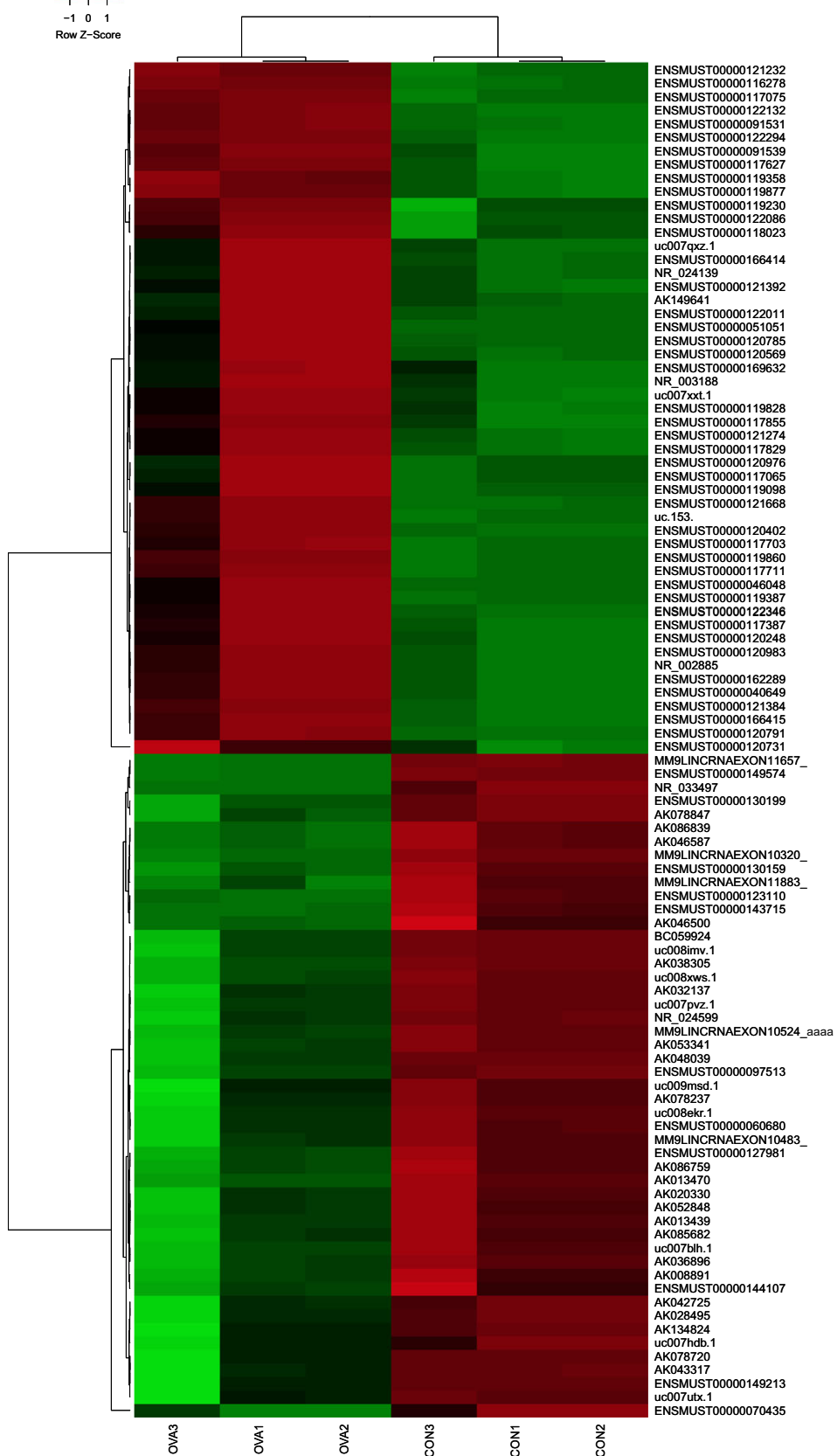

b
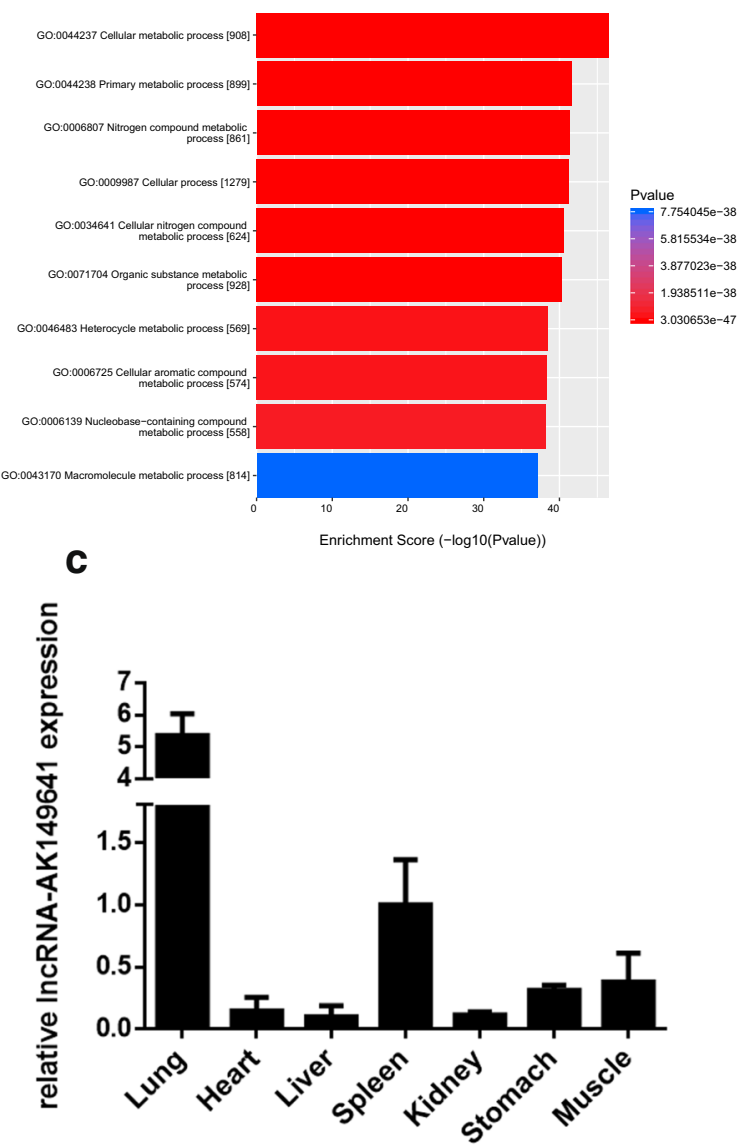

d

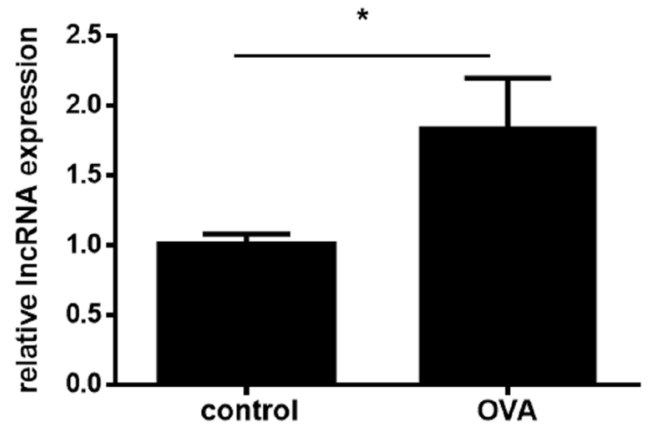

Fig. 1 Result of IncRNA microarray assays and distribution of IncRNA-AK149641 in female BALB/c mice. (A) The heat map of significantly differentially expressed IncRNAs between OVA mice and control mice. (Mice used for microarray assays were not infected with AAV6; CON1, CON2, and CON3 stood for control mice; OVA1, OVA2 and OVA3 stood for OVA mice). (B) The GO analysis, mainly

ontology (GO) was performed (Fig. 1B). The bar plot showed the top ten of the fold enrichment value of the significant enrichment terms. LncRNA microarray analysis showed that IncRNA-AK149641 expressed differentially in OVA mice (fold change: 4.52), consistent with our previous unpublished study in vitro. To further investigate the distribution of lncRNA-AK149641 in vivo, different organs referred to biological process (BP). (C) Distribution of lncRNAAK149641 in different organs, qRT-PCR showed that lncRNAAK149641 expressed the most in the lung tissue. $(n=6)$. (D) LncRNAAK149641 expressed higher in OVA mice, as determined by qRT-PCR. $(* P<0.05, n=5)$

from female BALB/c mice were obtained. QRT-PCR revealed that expression of IncRNA-AK149641 in the lung tissue was four to five times higher than that in other organs, as shown in Fig.1C. Moreover, we also found that in OVA mice, IncRNA-AK149641 upregulated significantly (Fig.1D). Therefore, we focused on lncRNA-AK149641 in the subsequent study. 


\section{Establishment of mouse model}

Protocol of establishment of OVA-induced asthma mouse model was showed in Fig. 2A. Twenty-four hours after last challenge, lung tissues and BALF were obtained, and AHR was measured.

\section{Infection of AAV6-shRNA-AK149641 decreased the expression of IncRNA-AK149641 in the lung tissue}

Analysis of frozen lung tissue slices showed that AAV6 successfully infected the lung tissue, as GFP was observed by using fluorescence microscopy (Fig. 2B). As shown in Fig. 2C, IncRNA-AK149641 expressed higher in OVA mice compared with non-OVA mice. On the other hand, when infected with AAV6-shRNA-AK149641, expression of lncRNAAK149641 was reduced, with statistical significance, suggesting that AAV6-shRNA-AK149641 significantly downregulated lncRNA-AK149641 expression in the lung tissue.

\section{Downregulation of IncRNA-AK149641 attenuated AHR in OVA mice}

Twenty-four hours after the last challenge, AHR was measured following methacholine (Mch) challenge. As shown in Fig. 3A, B, increasing concentrations of Mch significantly decreased airway compliance (Cydn) and increased asthmatic expiratory airway resistance $\left(\mathrm{R}_{\mathrm{e}}\right)$ in OVA mice. However, when IncRNA-AK149641 was downregulated in OVA mice, these changes were inhibited. Of note, downregulation of IncRNA-AK149641 had no effect on non-OVA mice in aspect of AHR. Taken together, downregulation of IncRNAAK149641 showed a benefit on AHR in OVA mice.

\section{Downregulation of IncRNA-AK149641 significantly reduced total cell counts and eosinophil counts in BALF of OVA mice}

To identify whether IncRNA-AK149641 could affect the infiltration of inflammatory cells in OVA mice, BALF
Fig. 2 AAV6 infected the lung tissue and AAV6-shRNA-

AK149641 downregulated the expression of IncRNAAK149641 successfully. (A) Brief protocol for the establishment of OVA-induced asthma mouse model. (B) GFP was observed in the lung tissue of mice which infected with AAV6 (b), while it was negative in the mice without AAV6 infection (a), suggesting that AAV6 infected the lung tissue successfully. (C) Different expressions of IncRNAAK149641 in the lung tissue with different interventions, as determined by qRT-PCR. The expression of lncRNA-AK149641 expressed higher in the OVA mice. Infected with AAV6shRNA-AK149641 showed lower expression, with statistical difference, suggesting that AAV6shRNA-AK149641 could successfully down-regulate the expression of lncRNA-AK149641. $(* P<0.05, * * P<0.01$, $* * * P<0.001, n=6$ )
A

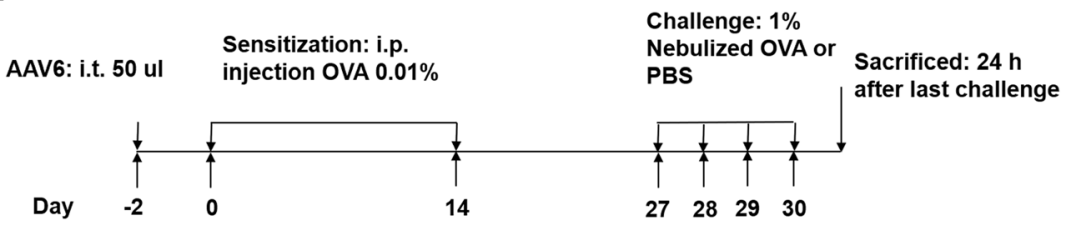

B
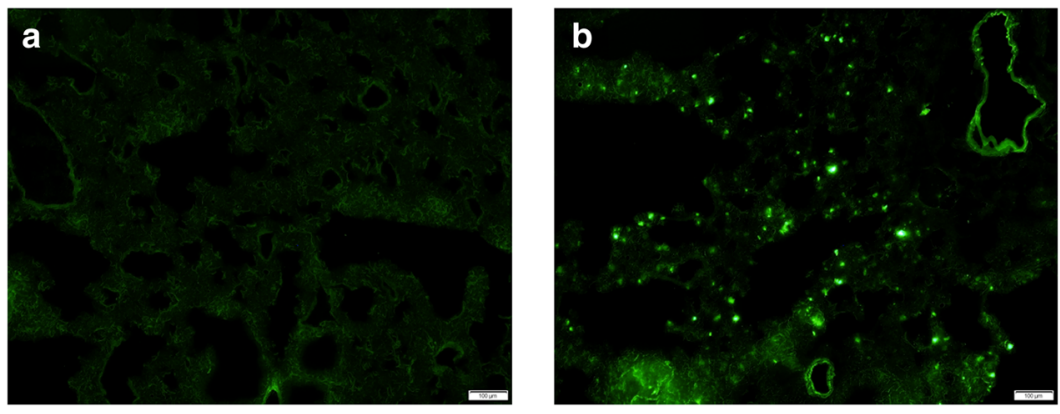

C

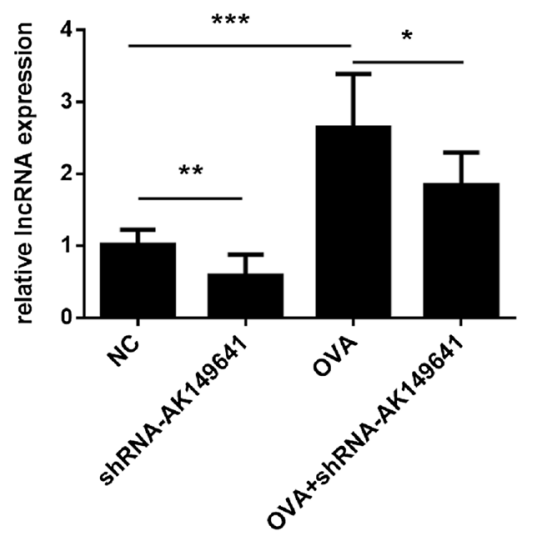



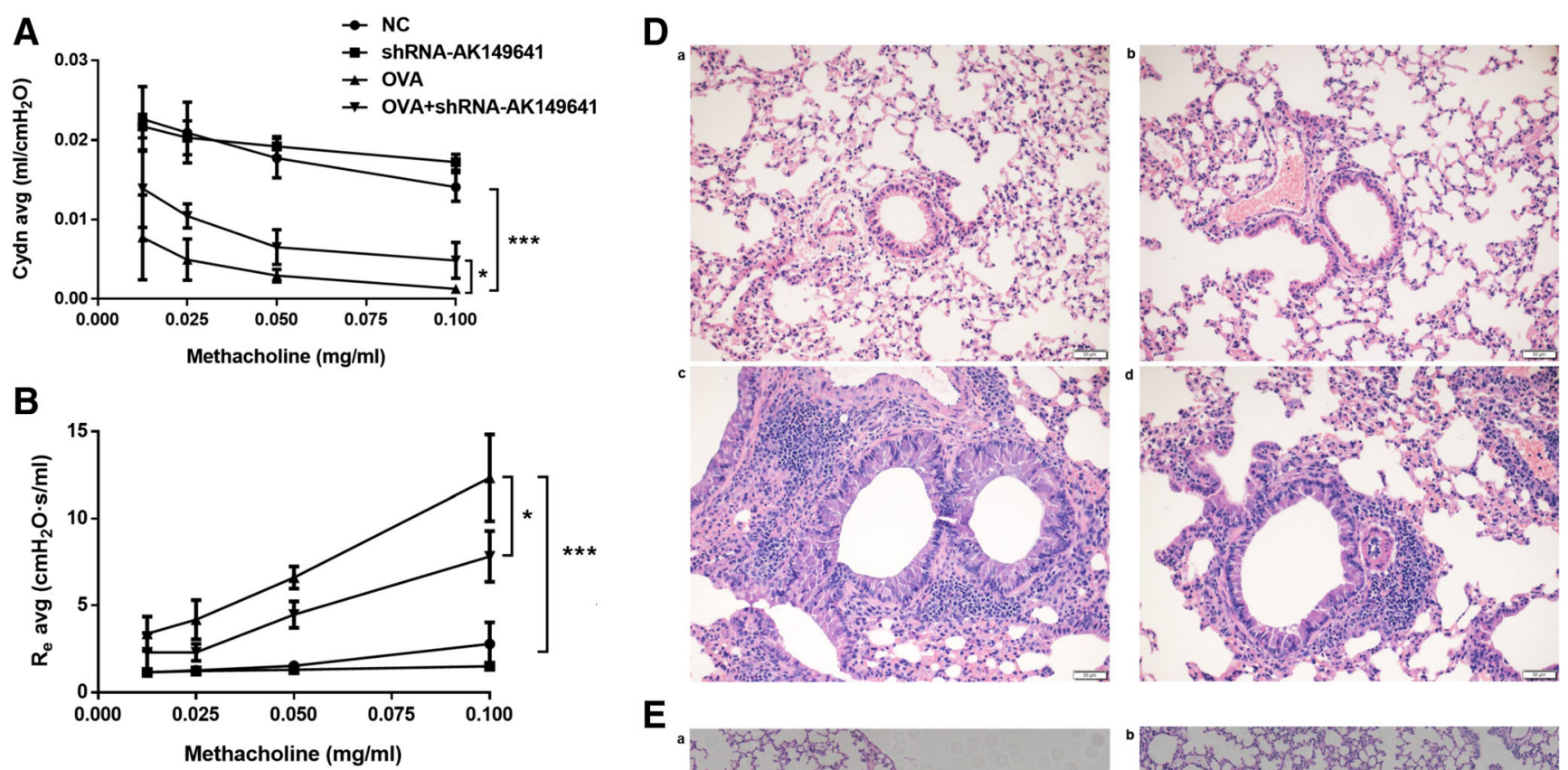

E
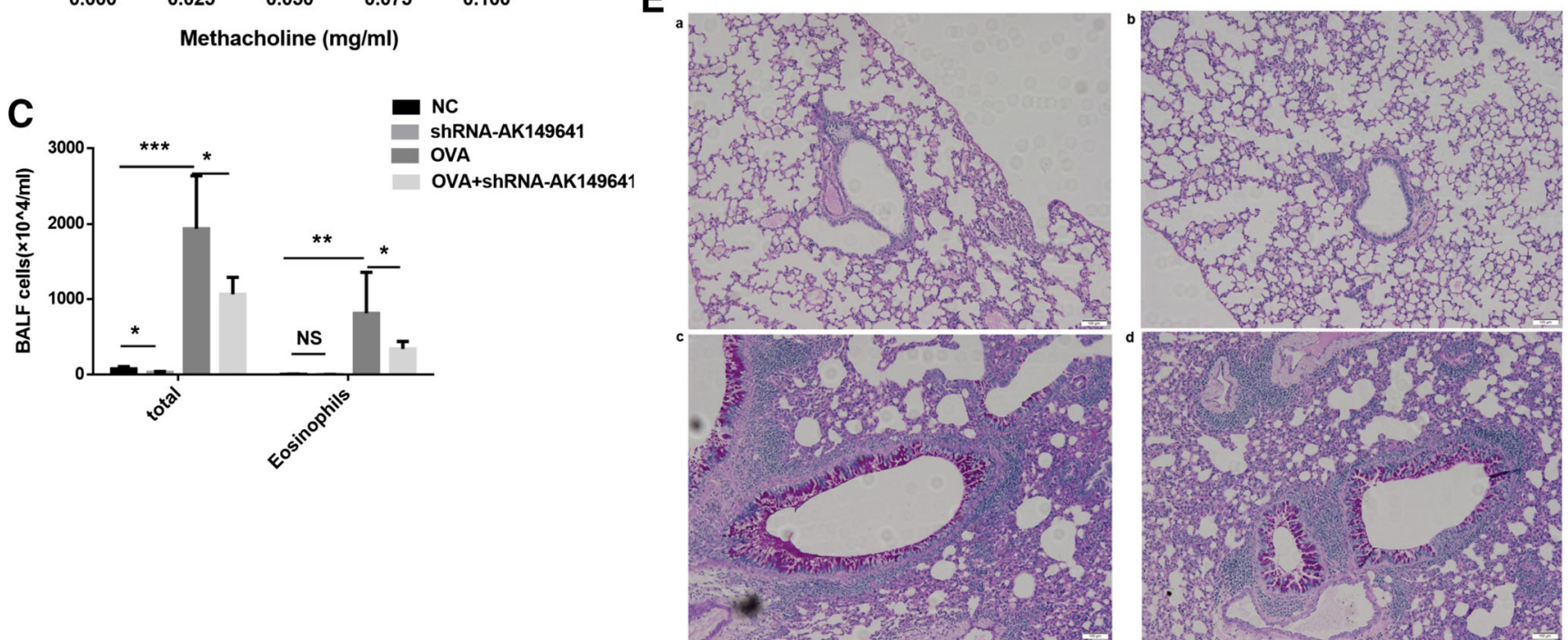

Fig. 3 Downregulation of IncRNA-AK149641 attenuated the airway inflammatory response in OVA mice. (A) Airway compliance (Cydn) decreased and $(B)$ airway resistance $\left(\mathrm{R}_{\mathrm{e}}\right)$ increased in the OVA mice, while downregulating lncRNA-AK149641 weakened the changes, when the concentration of methacholine was over $0.0125 \mathrm{mg} / \mathrm{ml}$. $(* * P<0.05$, $n=4)$. (C) Total inflammatory cells and eosinophils infiltrated higher in BALF of OVA mice, while downregulating lncRNA-AK149641 reduced the infiltrations. All the differences were statistically significant. $(* P<0.05, * * P<0.01, * * * P<0.001 ; n=6)$. (D) H\&E staining of the

samples were obtained and examined. As shown in Fig. $3 \mathrm{C}$, OVA mice exhibited robust increases in total cell counts and eosinophil counts, while downregulating lncRNA-AK149641 significantly decreased the infiltration of inflammatory cells. In contrast, non-OVA mice exhibited minimal inflammatory cell numbers in BALF and lower expression of IncRNA-AK149641 had no effect on eosinophil counts. Thus, downregulation of lncRNAAK149641 attenuated asthmatic airway inflammation by reducing infiltration of inflammatory cells. lung tissue. Downregulation of lncRNA-AK149641 mitigated the peribronchial infiltration of inflammatory cells in OVA mice. (E) PAS staining of the lung tissue. Downregulation of lncRNA-AK149641 mitigated the production of mucus in OVA mice. (F) Immunohistochemical staining of TNF- $\alpha$ and (G) IL- 6 in lung tissue. Downregulation of IncRNA-AK149641 decreased expression of TNF- $\alpha$ and IL-6 in OVA mice. (a. NC, b. shRNA-AK149641, c. OVA, d. OVA+shRNAAK149641). $(n=6)$

\section{Downregulation of IncRNA-AK149641 reduced infil- tration of inflammatory cells and production of mucus in the lung tissue of OVA mice}

Microscopically, exposure to OVA markedly increased peribronchial infiltration of inflammatory cells compared with non-OVA mice, and downregulation of IncRNA-AK149641 mitigated the infiltration, as shown by H\&E staining (Fig. 3D), which was consistent with the result obtained in the BALF analysis. With low expression of lncRNA-AK149641 
F

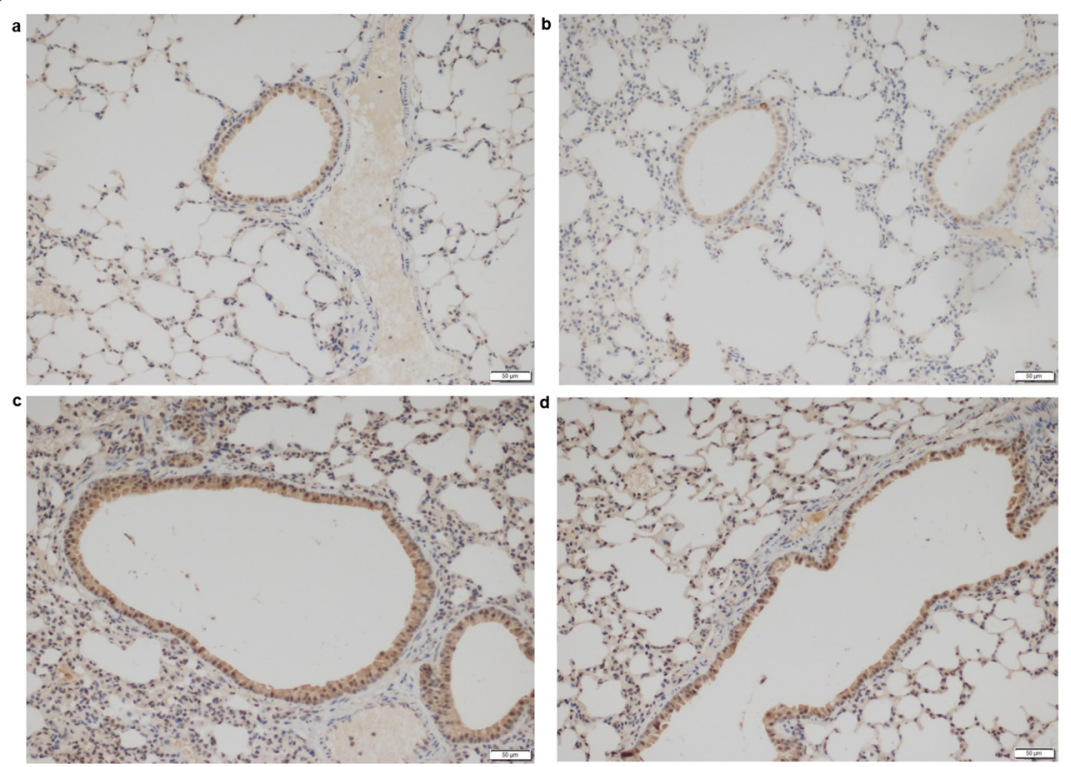

G

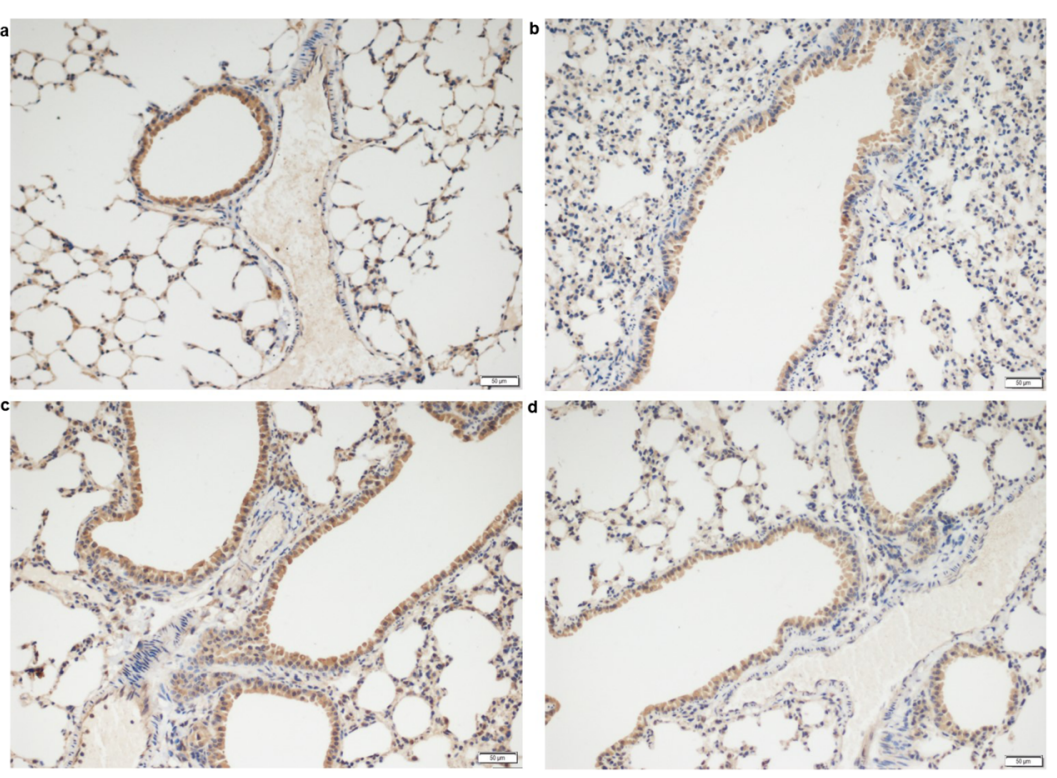

Fig. 3 (continued)

in OVA mice, PAS staining of the lung tissue showed that mucus production was also dramatically decreased (Fig. 3E). Based on histological evaluation, we concluded that downregulation of IncRNA-AK149641 mitigated the peribronchial infiltration of inflammatory cells and production of mucus.

\section{Downregulation of IncRNA-AK149641 decreased TNF- $\alpha$ and IL- 6 in OVA mice}

Concentrations of TNF- $\alpha$ and IL- 6 in the lung tissue were assessed by immunohistochemistry to determine whether lncRNA-AK149641 affected their expressions. Both inflammatory factors were highly expressed in OVA mice. However, infection of AAV6-shRNA-AK149641 resulted in significantly lower expression levels of TNF- $\alpha$ and IL-6 (Fig. 3F, G).

\section{Activity of NF-KB signaling pathway decreased in IncRNA-AK149641 downregulated mice}

As shown in Fig. 4A, B, compared to non-OVA mice, expressions of phosphorylated NF-kB p65 (p-NF-kB p65) and MyD88, as determined by western blot, were increased in OVA mice, whereas downregulation of lncRNA-AK149641 significantly decreased their expression levels. In summary, we determined that IncRNA-AK149641 participated in the asthma-associated inflammatory response via the NF-KB 


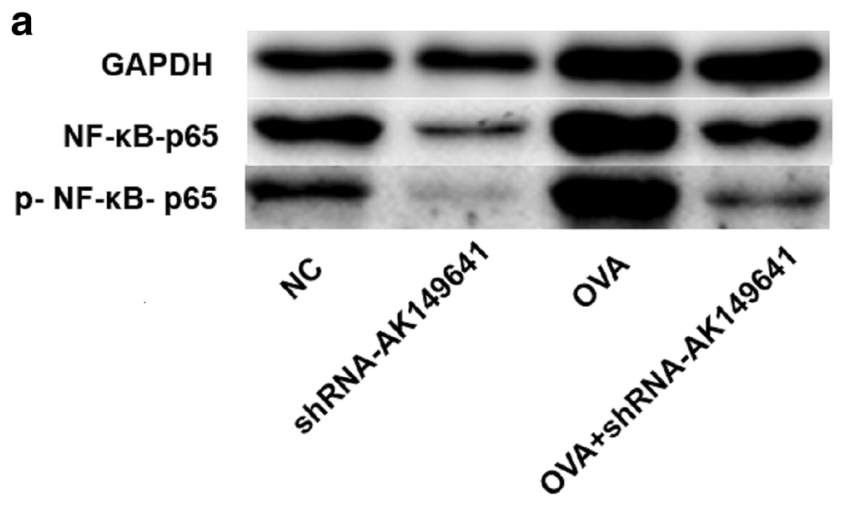

b

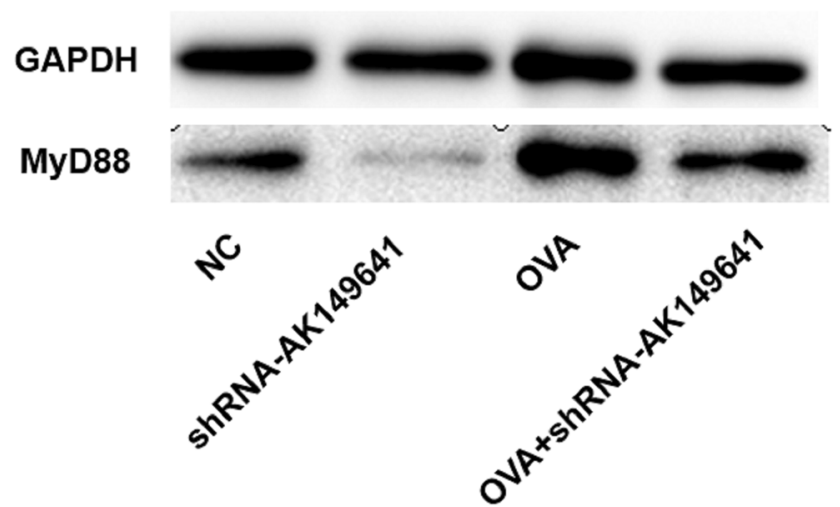

Fig. 4 Changes in protein expression of NF- $\kappa$ B signaling pathway components in response to different IncRNA-AK149641 levels. (A) p-NF-kB p65 and (B) MyD88 protein levels in lung tissue, as determined by western blot. (repeated three times)

signaling pathway probably by regulating expressions of $\mathrm{p}$ NF- $\mathrm{BB}$ p65 and MyD88.

\section{Discussion}

Microarray analysis revealed that there were differentially expressed lncRNAs between the lung tissue of OVA mice and control mice. Another study (Zhu et al. 2018) found 41 dysregulated lncRNAs (difference $\geq 2$-fold) in blood samples from patients with eosinophilic asthma, compared to the healthy individuals', supporting that lncRNAs were related to asthma. Deeper researches focused on the mechanism on how IncRNAs regulated asthma. Lin et al. proposed that lncRNA TUG1 promoted ASMCs proliferation and migration via sponging miR-590-5p/FGF1 in asthma (Lin et al. 2019a). LncRNA TCF7 was found to be contributed to the growth and migration of ASMCs in asthma through targeting TIMMDC1/ Akt axis (Fan et al. 2019).

TNF- $\alpha$ and IL- 6 are major pro-inflammatory cytokines involved in asthma. In asthma mouse model, anti-TNF- $\alpha$ treatment attenuated airway inflammation (Kim et al. 2006). Moreover, anti-TNF therapy resulted in clinical improvement of AHR, lung function and quality-of-life of patients with asthma, together with a reduction in exacerbation frequency (Berry et al. 2007). IL-6 is related to asthma severity. Sputum IL-6 level was inversely related to FEV1 (\% predicted) and positively correlated with the Asthma Control Questionnaire (ACQ) score (Morjaria et al. 2010).

LncRNAs and pro-inflammatory cytokines are closely associated with inflammation. Our results revealed that expressions of TNF- $\alpha$ and IL- 6 were lower in OVA mice upon downregulating lncRNA-AK149641, suggesting that lncRNAs and cytokines may cooperate to modulate inflammation. In human abdominal aortic aneurysm, IL-6 induced the activity of NOX2 in the aortic endothelial cells via the induction of the IncRNA MALAT1 by an ERK-dependent mechanism (Wang et al. 2016). The lincRNA THRIL, whose expression levels correlated with the severity of Kawasaki disease, induced expression of TNF- $\alpha$ by forming a ribonucleoprotein (RNP) complex with hnRNPL (Li et al. 2014).

PAS staining showed that secretion of mucus decreased in lncRNA-AK149641 downregulated OVA mice, suggesting that lncRNA-AK149641 maybe a regulator of mucus production. A recent study also revealed that linc00632 inhibited IL13-induced muac5ac production in nasal epithelial cells (Yue et al. 2020).

LncRNAs and different cell types were involved in the pathophysiology of asthma. Studies showed that increased lncRNA H19 inhibited the function of goblet cells, thus potentially contributing to barrier dysfunction in intestinal pathologies ( $\mathrm{Yu}$ et al. 2020). H19 was found differentially expressed in OVA mice in our microarray analysis, thus, H19 could also potentially regulate inflammation of asthma by targeting goblet cells. LncRNA-AK085865 depletion can ameliorate the inflammation of dermatophagoides farinae protein 1-induced allergic asthma by modulation macrophage polarization (Pei et al. 2020). In human patients with asthma, IncRNA-MEG3 regulated Treg/Th17 balance (Qiu et al. 2019). Many reports revealed that lncRNAs regulated asthmatic inflammation through ASMCs. Upregulation of MALAT1 took part in plateletderived growth factor (PDGF)-BB-induced ASMC proliferation and migration (Lin et al. 2019b). LINC00882 contributes to PDGF-induced proliferation of human fetal ASMCs by enhancing Wnt/ $\beta$-catenin signaling via miR-3619-5p. Glucocorticoid is an important treatment for asthma, while IncRNA GAS5 is a decoy for glucocorticoid receptor. In asthmatic rats, GAS5 promotes ASMC proliferation by miR-10a/ BDNF signaling pathway (Zhang et al. 2018). Christine et.al. found that proinflammatory mediators up-regulate GAS5 levels in both airway epithelial and smooth muscle cell, and that decreasing GAS5 levels can enhance glucocorticoid action in airway epithelial cells.

The transcription factor $\mathrm{NF}-\mathrm{KB}$ is an essential regulator in inflammation, immunity, differentiation, and cell proliferation (Ruland 2011). The NF-KB family consists of five subunits: 
p50, p52, p65 (RelA), c-Rel, and RelB. Among which, p65 (RelA), c-Rel, and RelB obtain transcription activation domain and usually activate gene transcription. Recent studies have shown that lncRNAs take part in pathophysiological process by regulating NF- $\mathrm{KB}$ signaling pathway. Wang et al. reported that IncRNA BANCR regulated NF-kB1 (P50/105) via miR-9 to influence cell growth and apoptosis in gastric cancer (Zhang et al. 2015). LPS induced lncRNA, Mirt2, specifically inhibited the K63-ubiquitination of TRAF6, and thus, inhibiting the activation of NF-KB and MAPK pathways to limit production of proinflammatory cytokines (Du et al. 2017). LncRNA NKILA inhibited IKK-induced IKB phosphorylation and NF- $\mathrm{KB}$ activation by forming a stable complex with NF- $\mathrm{KB} / \mathrm{I} \kappa \mathrm{B}$, thus preventing over-activation of NF- $\mathrm{KB}$ pathway to suppress breast cancer metastasis (Liu et al. 2015).

Downregulation of lncRNA-AK149641 in OVA mice resulted in significant decrease in the protein levels of p-NF- $\mathrm{kB}$ p65, providing a potential possibility that IncRNA-AK149641 regulates NF- $\mathrm{KB}$, probably through $\mathrm{p} 65$ subunit. In endothelial cells, TNF- $\alpha$ induced the expression of lncRNA ANRIL through NF-kB/p65. When bound to the transcriptional factor YY1, ANRIL regulated expressions of IL-6 and IL-8, downstream of NF-KB signaling pathway (Zhou et al. 2015b). In mouse tubular epithelial cells, IncRNA Arid2-IR played the promoter role in NF-K B-dependent renal inflammation by infecting IL-1 $\beta$-induced phosphorylation and DNA binding activity of NFKB/p65 (Zhou et al. 2015a). As for our study, to better understand how IncRNA-AK149641 regulates NF- $\mathrm{KB}$ signaling pathway, electrophoretic mobility shift assays (EMSA) and RNA binding protein immunoprecipitaiton (RIP) will be done in the future.

In summary, downregulation of IncRNA-AK149641 in OVA mice attenuated AHR, decreased infiltrations of inflammatory cells in BALF and peribronchia, reduced secretions of TNF- $\alpha$, IL- 6 and glycogen, in association with decreased expression of MyD88, and p-NF-kB p65. We propose that IncRNA-AK149641 regulates the asthma-associated airway inflammatory response by targeting the NF- $\mathrm{KB}$ signaling pathway.

Acknowledgements The work was supported by Nanjing Medical Science and Technique Development Foundation (JQX15008), National Natural Science Foundation of China (81700035), Jiangsu Province Young Medical Talents (QNRC2016087), Nanjing Science and Technology Commission (Social Development) (201723003), Southeast University-Nanjing Medical University Cooperative Research Project (2242018K3DN20), Key Projects of Nanjing Health and Planning Commission (ZKX18041), General Projects of Nanjing Health and Planning Commission (YKK18194) and Project of Nanjing Medical University (2017njmuzd054).

Availability of data and material Yes Code availability Not applicable.

Authors' contributions Conceptualization: Deyu Zhao, Feng Liu.
Methodology: Jie Zhang, Yao Zhou, Haiyan Gu, Heng Tang, Qiangquan Rong, Lina Gu, Jing Pan.

Formal analysis and investigation: Jie Zhang, Yao Zhou,

Writing-original draft preparation: Jie Zhang.

Writing-review and editing: Jie Zhang, Yao Zhou, Deyu Zhao and Feng Liu.

Funding acquisition: Yao Zhou, Heng Tang, Qiangquan Rong, Deyu Zhao, Feng Liu.

Supervision: Deyu Zhao, Feng Liu.

Funding The work was supported by National Natural Science Foundation of China (81700035), Jiangsu Province Young Medical Talents (QNRC2016087), Nanjing Medical Science and Technique Development Foundation (JQX15008), Nanjing Science and Technology Commission (Social Development) (201723003), Southeast University-Nanjing Medical University Cooperative Research Project (2242018K3DN20), Key Projects of Nanjing Health and Planning Commission (ZKX18041), General Projects of Nanjing Health and Planning Commission (YKK18194) and Project of Nanjing Medical University (2017njmuzd054).

\section{Compliance with ethical standards}

The study reported here complies with ethical requirements and is permitted by the Animal Ethical and Welfare Committee (AEWC) of Nanjing Medical University (Approval No. IACUC-1703005).

Conflict of interest The author declare no conflict of interest.

Ethics approval Approval No. IACUC-1703005.

Consent to participate Not applicable.

Consent for publication Yes

Open Access This article is licensed under a Creative Commons Attribution 4.0 International License, which permits use, sharing, adaptation, distribution and reproduction in any medium or format, as long as you give appropriate credit to the original author(s) and the source, provide a link to the Creative Commons licence, and indicate if changes were made. The images or other third party material in this article are included in the article's Creative Commons licence, unless indicated otherwise in a credit line to the material. If material is not included in the article's Creative Commons licence and your intended use is not permitted by statutory regulation or exceeds the permitted use, you will need to obtain permission directly from the copyright holder. To view a copy of this licence, visit http://creativecommons.org/licenses/by/4.0/.

\section{References}

Berry M, Brightling C, Pavord I, Wardlaw A (2007) TNF-alpha in asthma. Curr Opin Pharmacol 7:279-282. https://doi.org/10.1016/j. coph.2007.03.001

Chiang CH, Chuang CH, Liu SL, Shen HD (2013) Genetic polymorphism of transforming growth factor 1 and tumor necrosis factor is associated with asthma and modulates the severity of asthma. Resp Care 58:1343-1350. https://doi.org/10.4187/respcare.02187

Daneshmandi S, Pourfathollah AA, Pourpak Z, Heidarnazhad H, Kalvanagh PA (2011) Cytokine gene polymorphism and asthma susceptibility, progress and control level. Mol Bio Rep 39:18451853. https://doi.org/10.1007/s11033-011-0927-7 
Dienz O, Rincon M (2009) The effects of IL-6 on CD4 T cell responses. Clin Immunol 130:27-33. https://doi.org/10.1016/j.clim.2008.08. 018

Doganci A, Eigenbrod T, Krug N, de Sanctis GT, Hausding M, Erpenbeck VJ, Haddad el-B, Lehr HA, Schmitt E, Bopp T, Kallen KJ, Herz U, Schmitt S, Luft C, Hecht O, Hohlfeld JM, Ito H, Nishimoto N, Yoshizaki K, Kishimoto T, Rose-John S, Renz H, Neurath MF, Galle PR, Finotto S (2005) The IL-6R $\alpha$ chain controls lung CD4+CD25+ Treg development and function during allergic airway inflammation in vivo. J Clin Invest 115:313-325. https://doi. org/10.1172/jci200522433

Doherty TA, Croft M (2011) Therapeutic potential of targeting TNF/ TNFR family members in asthma. Immunotherapy 3:919-921. https://doi.org/10.2217/imt.11.88

$\mathrm{Du} \mathrm{M}$ et al (2017) The LPS-inducible lncRNA Mirt2 is a negative regulator of inflammation. Nat Commun 8:2049. https://doi.org/10. 1038/s41467-017-02229-1

Fan M, Xu J, Xiao Q, Chen F, Han X (2019) Long non-coding RNA TCF7 contributes to the growth and migration of airway smooth muscle cells in asthma through targeting TIMMDC1/Akt axis. Biochem Biophys Res Commu 508:749-755. https://doi.org/10. 1016/j.bbrc.2018.11.187

Ford JG, Rennick D, Donaldson DD, Venkayya R, McArthur C, Hansell E, Kurup VP, Warnock M, Grünig G (2001) IL-13 and IFN- $\gamma$ : interactions in lung inflammation. J Immunol 167:1769-1777. https://doi.org/10.4049/jimmunol.167.3.1769

Galli SJ, Borregaard N, Wynn TA (2011) Phenotypic and functional plasticity of cells of innate immunity: macrophages, mast cells and neutrophils. Nat Immunol 12:1035-1044. https://doi.org/10.1038/ ni.2109

Houtman M, Shchetynsky K, Chemin K, Hensvold AH, Ramsköld D, Tandre K, Eloranta ML, Rönnblom L, Uebe S, Catrina AI, Malmström V, Padyukov L (2018) T cells are influenced by a long non-coding RNA in the autoimmune associated PTPN2 locus. J Autoimmun 90:28-38. https://doi.org/10.1016/j.jaut.2018.01.003

Kim HY, DeKruyff RH, Umetsu DT (2010) The many paths to asthma: phenotype shaped by innate and adaptive immunity. Nat Immunol 11:577-584. https://doi.org/10.1038/ni.1892

Kim J, McKinley L, Natarajan S, Bolgos GL, Siddiqui J, Copeland S, Remick DG (2006) Anti-tumor necrosis factor-alpha antibody treatment reduces pulmonary inflammation and methacholine hyperresponsiveness in a murine asthma model induced by house dust. Clin Exp Allergy 36:122-132. https://doi.org/10.1111/j.1365-2222. 2005.02407.x

Lee SY, Bae CS, Seo JH, Cho S, Bae MS, Oh DS, Park DH (2017) Mycoleptodonoides aitchisonii suppresses asthma via Th2 and Th1 cell regulation in an ovalbumin-induced asthma mouse model. Mol Med Rep 17:11-20. https://doi.org/10.3892/mmr.2017.7901

Li J, Li L, Liu X, Li R, Yang X (2013) Single-wall carbon nanotubeinduced airway hyperresponsiveness in rats and a postulated mechanism of action. RSC Adv 3:25388-25395. https://doi.org/10.1039/ c3ra44168g

Li Y, Pan X, Peng X, Li S, Zhou Y, Zheng X, Li M (2015) Adenovirusmediated interleukin-35 gene transfer suppresses allergic airway inflammation in a murine model of asthma. Inflamm Res 64:767-774. https://doi.org/10.1007/s00011-015-0858-1

Li YF, Gauderman WJ, Avol E, Dubeau L, Gilliland FD (2006) Associations of tumor necrosis factor G-308A with childhood asthma and wheezing. Am J Respir Crit Care Med 173:970-976. https:// doi.org/10.1164/rccm.200508-1256OC

Li Z, Chao TC, Chang KY, Lin N, Patil VS, Shimizu C, Head SR, Burns JC, Rana TM (2014) The long noncoding RNA THRIL regulates TNF alpha expression through its interaction with hnRNPL. Proc Natl Acad Sci U S A 111:1002-1007. https://doi.org/10.1073/pnas. 1313768111
Lin J, Feng X, Zhang J, Tong Z (2019a) Long noncoding RNA TUG1 promotes airway smooth muscle cells proliferation and migration via sponging miR-590-5p/FGF1 in asthma. Am J Transl Res 11: 3159-3166

Lin L, Li Q, Hao W, Zhang Y, Zhao L, Han W (2019b) Upregulation of lncRNA malat1 induced proliferation and migration of airway smooth muscle cells via miR-150-eIF4E/Akt signaling. Front Physiol 10:1337. https://doi.org/10.3389/fphys.2019.01337

Liu B, Sun L, Liu Q, Gong C, Yao Y, Lv X, Lin L, Yao H, Su F, Li D, Zeng M, Song E (2015) A cytoplasmic NF-kappaB interacting long noncoding RNA blocks IkappaB phosphorylation and suppresses breast cancer metastasis. Cancer Cell 27:370-381. https://doi.org/ 10.1016/j.ccell.2015.02.004

Morjaria JB, Babu KS, Vijayanand P, Chauhan AJ, Davies DE, Holgate ST (2010) Sputum IL-6 concentrations in severe asthma and its relationship with FEV1. Thorax 66:537-537. https://doi.org/10. 1136/thx.2010.136523

Myou S, Leff AR, Myo S, Boetticher E, Tong J, Meliton AY, Liu J, Munoz NM, Zhu X (2003) Blockade of inflammation and airway hyperresponsiveness in immune-sensitized mice by dominantnegative phosphoinositide 3-kinase-TAT. J Exp Med 198:15731582. https://doi.org/10.1084/jem.20030298

Neveu WA, Allard JL, Raymond DM, Bourassa LM, Burns SM, Bunn JY, Irvin CG, Kaminsky DA, Rincon M (2010) Elevation of IL-6 in the allergic asthmatic airway is independent of inflammation but associates with loss of central airway function. Respir Res 11:28. https://doi.org/10.1186/1465-9921-11-28

Pei W, Zhang Y, Li X, Luo M, Chen T, Zhang M, Zhong M, Lv K (2020) LncRNA AK085865 depletion ameliorates asthmatic airway inflammation by modulating macrophage polarization. Int Immunopharmacol 83:106450. https://doi.org/10.1016/j.intimp. 2020.106450

Qiu YY, Wu Y, Lin MJ, Bian T, Xiao YL, Qin C (2019) LncRNA-MEG3 functions as a competing endogenous RNA to regulate Treg/Th17 balance in patients with asthma by targeting microRNA-17/ ROR $\gamma$ t. Biomed Pharmacother 111:386-394. https://doi.org/10.1016/j. biopha.2018.12.080

Rameshwar P, Yang G, Chen J, Xu F, Bao Z, Yao Y, Zhou J (2014) Association between tumor necrosis factor- $\alpha$ rs1800629 polymorphism and risk of asthma: a meta-analysis. PLoS One 9:e99962. https://doi.org/10.1371/journal.pone.0099962

Rincon M, Irvin CG (2012) Role of IL-6 in asthma and other inflammatory pulmonary diseases. Int J Biol Sci 8:1281-1290. https://doi.org/ $10.7150 /$ ijbs. 4874

Ruland J (2011) Return to homeostasis: downregulation of NF-kappaB responses. Nat Immunol 12:709-714. https://doi.org/10.1038/ni. 2055

Russo C, Polosa R (2005) TNF-alpha as a promising therapeutic target in chronic asthma: a lesson from rheumatoid arthritis. Clin Sci (Lond) 109:135-142. https://doi.org/10.1042/cs20050038

Suh DH, Trinh HK, Liu JN, Pham le D, Park SM, Park HS, Shin YS (2016) P2Y12 antagonist attenuates eosinophilic inflammation and airway hyperresponsiveness in a mouse model of asthma. J Cel Mol Med 20:333-341 doi:https://doi.org/10.1111/jcmm.12727

Tu J, Tian G, Cheung HH, Wei W, Lee TL (2018) Gas5 is an essential lncRNA regulator for self-renewal and pluripotency of mouse embryonic stem cells and induced pluripotent stem cells. Stem Cell Res Ther 9:71. https://doi.org/10.1186/s13287-018-0813-5

Wang Y, Nie W, Yao K, Wang Z, He H (2016) Interleukin 6 induces expression of NADPH oxidase 2 in human aortic endothelial cells via long noncoding RNA MALAT1. Pharmazie 71:592-597. https://doi.org/10.1691/ph.2016.6598

Wilson DH, Adams RJ, Tucker G, Appleton S, Taylor AW, Ruffin RE (2006) Trends in asthma prevalence and population changes in South Australia, 1990-2003. Med J Aust 184:226-229 
Yang L, Froberg JE, Lee JT (2014) Long noncoding RNAs: fresh perspectives into the RNA world. Trends Biochem Sci 39:35-43. https://doi.org/10.1016/j.tibs.2013.10.002

Yin DD, Zhang EB, You LH, Wang N, Wang LT, Jin FY, Zhu YN, Cao LH, Yuan QX, de W, Tang W (2015) Downregulation of lncRNA TUG1 affects apoptosis and insulin secretion in mouse pancreatic beta cells. Cell Physiol Biochem 35:1892-1904. https://doi.org/10. 1159/000373999

Yu TX, Chung HK, Xiao L, Piao JJ, Lan S, Jaladanki SK, Turner DJ, Raufman JP, Gorospe M, Wang JY (2020) Long noncoding RNA H19 impairs the intestinal barrier by suppressing autophagy and lowering paneth and goblet cell function. Cell Mol Gastroenterol Hepatol 9:611-625. https://doi.org/10.1016/j.jcmgh.2019.12.002

Yue L, Yin X, Hao F, Dong J, Ren X, Xu O, Shan C (2020) Long noncoding RNA linc00632 inhibits interleukin-13-induced inflammatory cytokine and mucus production in nasal epithelial cells. $\mathrm{J}$ Innate Immun 12:116-128. https://doi.org/10.1159/000500420

Zhang XY, Tang XY, Li N, Zhao LM, Guo YL, Li XS, Tian CJ, Cheng DJ, Chen ZC, Zhang LX (2018) GAS5 promotes airway smooth muscle cell proliferation in asthma via controlling miR-10a/BDNF signaling pathway. Life Sci 212:93-101. https://doi.org/10.1016/j. lfs.2018.09.002

Zhang XY, Zhang LX, Tian CJ, Tang XY, Zhao LM, Guo YL, Cheng DJ, Chen XL, Ma LJ, Chen ZC (2016) LncRNAs BCYRN1 promoted the proliferation and migration of rat airway smooth muscle cells in asthma via upregulating the expression of transient receptor potential 1. Am J Ttransl Res 8:3409-3418

Zhang ZX, Liu ZQ, Jiang B, Lu XY, Ning XF, Yuan CT, Wang AL (2015) BRAF activated non-coding RNA (BANCR) promoting gastric cancer cells proliferation via regulation of NF- $\mathrm{kB} 1$. Biochem Bioph Res Co 465:225-231. https://doi.org/10.1016/j.bbrc.2015. 07.158

Zhou Q, Huang XR, Yu J, Yu X, Lan HY (2015a) Long noncoding RNA Arid2-IR is a novel therapeutic target for renal inflammation. Mol Ther 23:1034-1043. https://doi.org/10.1038/mt.2015.31

Zhou X, Han X, Wittfeldt A, Sun J, Liu C, Wang X, Gan LM, Cao H, Liang Z (2015b) Long non-coding RNA ANRIL regulates inflammatory responses as a novel component of NF- $\mathrm{kB}$ pathway. RNA Biol 13:98-108. https://doi.org/10.1080/15476286.2015.1122164

Zhou X, Ye F, Yin C, Zhuang Y, Yue G, Zhang G (2015c) The interaction between MiR-141 and lncRNA-H19 in regulating cell proliferation and migration in gastric cancer. Cell Physiol Biochem 36: 1440-1452. https://doi.org/10.1159/000430309

Zhu YJ, Mao D, Gao W, Hu H (2018) Peripheral whole blood lncRNA expression analysis in patients with eosinophilic asthma. Medicine 97:e9817. https://doi.org/10.1097/md.0000000000009817

Publisher's note Springer Nature remains neutral with regard to jurisdictional claims in published maps and institutional affiliations. 